\title{
SYSTOLIC AND DIASTOLIC DYSFUNCTION IN PATIENTS WITH CIRRHOSIS
}

\author{
Ashok Kumar1, Sudeep Kumar ${ }^{2}$
}

${ }^{1}$ Director, Department of Cardiology, Mahavir Heart Institute, LCT Ghat, Patna, Bihar.

2Professor, Department of Cardiology, SGPGI, Lucknow.

ABSTRACT
BACKGROUND
Patients of cirrhosis have a hyperdynamic circulatory state. These patients have diastolic dysfunction and normal systolic function
at rest which is known as "cirrhotic cardiomyopathy". This study focuses on frequency of cardiac dysfunction particularly systolic
and diastolic dysfunction in cirrhosis and its relation with severity of liver disease.

\section{MATERIALS AND METHODS}

This prospective study included 70 cirrhotic patients and 20 controls, enrolled after excluding patients with significant comorbidities. Hepatic function status was assessed by biochemical tests and prothrombin time. The cardiac evaluation was done using ECG, echocardiography and serum brain natriuretic peptide. The echocardiographic parameters used for chamber quantification and evaluation of systolic and diastolic functions were as per American Society of Echocardiography recommendations. The diastolic functions were evaluated mainly using tissue Doppler imaging for studying diastolic velocity across mitral septal annulus (E: E's ratio) and mitral lateral annulus (E: E' L). The myocardial performance index (MPI) was also assessed.

\section{RESULTS}

In cirrhosis patients, median age was 45 years (Range 30 - 58) and 72\% were male. Tissue Doppler imaging studying E: E's and E: $\mathrm{E}_{\mathrm{L}}^{\prime}$ showed diastolic dysfunction in cirrhotics as compared to controls $(\mathrm{P}<0.001)$. Using cut-off E: E's ratio less than 8, the frequency of diastolic dysfunction in cirrhotics was $64.2 \%$. The median E deceleration time (ms) in cirrhotics and controls was 170 (100 - 229) and 204 (190-220) respectively and difference was statistically significant. $(\mathrm{P}<0.01)$. MPI was also statistically different in controls and cirrhotics $(\mathrm{P}<0.001)$. The cirrhosis group had increased left ventricular diastolic dimensions and shorter left ventricular systolic dimensions. The other parameters E: A ratio, Isovolumetric relaxation time (IVRT), interventricular septal thickness, posterior wall thickness, ejection fraction, QTc were not different among the two groups. There was no difference between alcoholic and non-alcoholic groups.

\section{CONCLUSION}

$64.2 \%$ cirrhotics had diastolic dysfunction, none had systolic dysfunction. There was no correlation between cardiac structural and functional parameters and the severity of liver disease. The cardiac changes were due to cirrhosis itself rather than the aetiology.

\section{KEYWORDS}

Cirrhosis Liver, Cardiomyopathy, Ventricular Dysfunction.

HOW TO CITE THIS ARTICLE: Kumar A, Kumar S. Systolic and diastolic dysfunction in patients with cirrhosis. J. Evolution Med. Dent. Sci. 2017;6(32):2650-2655, DOI: 10.14260/Jemds/2017/571

\section{BACKGROUND}

Cirrhosis is associated with various cardiovascular abnormalities, most of which have been recently recognised. The cardiovascular abnormalities associated with cirrhosis are hyperdynamic circulation, characterised by higher resting cardiac output, decreased systemic vascular resistance and blood pressure.1,2 Initially, these changes were correlated to alcohol rather than to cirrhosis. There are studies which have shown cardiovascular abnormalities in cirrhosis due to different aetiologies. ${ }^{2}$

With introduction of orthotopic liver transplantation, transjugular intrahepatic portosystemic shunts and surgical

Financial or Other, Competing Interest: None.

Submission 28-02-2017, Peer Review 08-04-2017,

Acceptance 14-04-2017, Published 20-04-2017.

Corresponding Author:

Dr. Ashok Kumar,

Director, Department of Cardiology,

Mahavir HEART Institute,

L.C.T. Ghat, Patna-800001, Bihar.

E-mail: ashok_74_kumar@yahoo.co.in

DOI: $10.14260 /$ jemds $/ 2017 / 571$

\section{(c) (i) $(5)$}

shunts in management of cirrhosis, adverse consequences of cardiac dysfunction have been recognised.3,4 Usually cardiac dysfunction remains latent and on strain or in response to vasoconstrictors, transient overt congestive heart failure may develop, along with increased cardiac output as well as right atrial, pulmonary artery and capillary wedge pressures.3,5

The cardiovascular dysfunction in cirrhosis is defined as cirrhotic cardiomyopathy. There is no precise definition of cirrhotic cardiomyopathy. World Congress of Gastroenterology (2005) defined it as a chronic cardiac dysfunction in patients with cirrhosis, characterised by blunted contractile responsiveness to stress and/or altered diastolic relaxation with electro-physiological abnormalities in absence of any known cardiac disease.

Without any confirmed diagnostic criteria, exact prevalence of systolic and diastolic dysfunction in cirrhosis is unknown. Its estimation is a difficult task as the cardiac disease is generally silent and shows itself only when the patient is subjected to stress such as body position changes, exercise, drugs, haemorrhage and surgery. The prevalence of liver cirrhosis is also difficult to estimate, because many patients with compensated cirrhosis do not exhibit signs or 
symptoms of the disease and because non-invasive studies lack sensitivity to detect cirrhosis at an early stage.

There is scanty data published on frequency of cardiac dysfunction in cirrhosis and its relation with severity of liver disease. This study was planned to observe the frequency of systolic and diastolic dysfunction in cirrhosis and its relation with severity of liver disease.

The serum brain natriuretic peptide (BNP) has been reported as a sensitive marker of ventricular dysfunction. ${ }^{6}$ Serum levels of BNP were measured and correlated with cardiac changes and severity of liver disease.

\section{MATERIALS AND METHODS}

This prospective study was conducted in Departments of Gastroenterology and Cardiology. Patients of cirrhosis admitted in gastroenterology ward and attending gastroenterology outpatient services were included. The diagnosis of cirrhosis was made by clinical assessment, biochemical tests, ultrasound and liver biopsy, if done. The severity of liver disease was calculated on basis of Child Pugh (CTP) score and model for end stage liver disease (MELD) score. All patients were haemodynamically stable and ambulatory. Patients with cirrhosis of different aetiologies were included in the study. The patients enrolled in study were on low sodium diet and had stopped diuretics for the last 7 days. Patients with severe anaemia, recent gastrointestinal bleed, diabetes, hypertension, on beta blockers and with primary cardiac or lung disease were excluded from the study. The controls were healthy population on normal diet without any dietary restriction.

The cardiac evaluation was done with electrocardiography (ECG) and 2-D transthoracic echocardiography (ECHO), by experienced cardiologists. The echocardiographic parameters used for chamber quantification and evaluation of systolic and diastolic function were as per American Society of Echocardiography recommendations.

Left ventricular (LV) dimensions were measured at the level of mitral leaflet tips or the papillary muscle using the parasternal view. The thickness of the ventricular posterior wall and the ventricular septum were measured from same M-mode echocardiogram. These values were used to calculate LV mass according to Devereux formula $\left(1.04\left[(\mathrm{LVID}+\mathrm{PWT}+\mathrm{IVST})^{3}-\mathrm{LVID}^{3}\right] \times 0.8+0.6\right)$ and the normal range of LV mass was 96 - 200 g. LA dimension was determined from parasternal long axis view at end systole and the normal dimension range was $2.7-4.0 \mathrm{~cm}$.

Parameters used in our study to evaluate systolic function were LV end diastolic volume (LVEDV), LV end systolic volume (LVESV) and LV ejection fraction (EF). EF which is expression of global LV function was measured using volumetric measurement i.e., (LVEDV-LVESV)/LVEDV. EF more than $55 \%$ was considered as normal.

Diastolic filling pattern which determines severity of diastolic dysfunction was estimated by measuring peak mitral flow velocity of the early rapid filling wave (E), peak velocity of the late filling wave $(\mathrm{A}), \mathrm{E} / \mathrm{A}$ ratio, $\mathrm{E}$ deceleration time (EDT) (the interval from the peak of the $\mathrm{E}$ velocity to its extrapolation to baseline), isovolumic relaxation time (IVRT) with pulsed wave Doppler technique. The normal E/A ratio is less than 1, EDT ranges from 170 - $240 \mathrm{~ms}$ and IVRT ranges from $80 \pm 20 \mathrm{~ms}$. With tissue Doppler imaging diastolic velocity across mitral septal annulus (E: E's ratio) and mitral lateral annulus (E: $\mathrm{E}_{\mathrm{L}}$ ratio) was calculated and the normal value of E: E's and E: E' ${ }_{L}$ ratios were less than 8 and 6.

\section{Measurement of Myocardial Performance Index}

The index is a Doppler-derived time interval index that combines both systolic and diastolic cardiac performance. The Tei index is easily derived using conventional pulsed Doppler echocardiography, as previously described by Tei and colleagues (Figure 1). 8 Doppler time intervals were measured from mitral inflow and left ventricular outflow Doppler tracings, as described by Tei and co-workers. ${ }^{2}$ The interval ' $a$ ' from cessation to onset of mitral inflow is equal to the sum of isovolumic contraction time (IVCT), isovolumic relaxation time (IVRT) and left ventricular ejection time (RVET). LVET ' $b$ ' is measured from the apical 4 chamber view with a pulse wave Doppler signal placed at the aortic valve annulus in the LV outflow tract. The sum of isovolumic contraction time (IVCT) and isovolumic relaxation time (IVRT) was obtained by subtracting ' $b$ ' from ' $a$ '. The Tei index was calculated as $a-b / b$. Isovolumic relaxation time was measured by subtracting the interval ' $\mathrm{d}$ ' between the $\mathrm{R}$ wave and cessation of left ventricular outflow from the interval ' $c$ ' between the $\mathrm{R}$ wave and the onset of mitral inflow. Isovolumic contraction time was calculated by subtracting IVRT from a-b. Each interval was measured on 5 consecutive beats and then averaged to account for slight variation in cycle lengths. The mean normal value of the Tei index is 0.39 0.05 for the LV, 8 while for the right ventricle (RV) it is 0.28 . In adults, values of the $\mathrm{LV}$ index $<0.40$ and for the $\mathrm{RV}<0.30$ are considered normal. Higher index values correspond to more pathological states with overall cardiac dysfunction.

The electrocardiographic QTc interval was calculated on basis of Bazett's formula - QT $/ \sqrt{R R}$.

The analysis of serum BNP levels was performed with commercially available Triage Meters for the rapid in vitro quantitative measurement of B-Type Natriuretic Peptide (BNP) in human whole-blood or plasma specimens using EDTA as the anticoagulant.

\section{Statistical Analysis}

The results of demographic, biochemical, severity score and Echocardiographic findings were expressed in median and range. The MELD score was calculated using UNOS calculator available online. Echocardiographic findings were compared between controls and diseased group (Alcoholic and nonalcoholic groups).

The continuous and categorical data was analysed using Mann-Whitney test and Chi-Square test, respectively. Kruskal-Wallis $\mathrm{H}$ test was used for comparing more than two continuous groups. Correlation was done using Pearson correlation test. The p-value less than 0.05 were considered as significant.

\section{RESULTS}

\section{Demographic Profile}

Age was comparable among cirrhotics and controls. 51 out of $70(73 \%)$ in cirrhosis group and 17 out of 20 (85\%) among controls were males. The different aetiologies of cirrhosis in the study were alcohol $(n=20)$, Hepatitis B related cirrhosis $(n=19)$, Hepatitis $C$ related cirrhosis $(n=18)$ and cryptogenic cirrhosis $(\mathrm{n}=13)$. 
The numbers of patients in Child A, Child B and Child C groups were 17, 22 and 31. The median MELD score in cirrhotics was 14 (Range 3 - 27), in alcoholics was 18 (Range 6-25) compared to 12 (Range 3-27) among nonalcoholics.

\section{Cardiac Evaluation}

On echocardiography, there was increased left ventricular diastolic dimension (LVDD) and decreased left ventricular systolic dimensions (LVSD) in cirrhotic group as compared to controls (Table 2). The difference of septal wall thickness (SWT) and posterior wall thickness (PWT) in diastole was not statistically significant on comparing cirrhotics to controls. The left atrial size was comparable among cirrhotics and controls. The LV mass was more in cirrhotics but this difference was not statistically significant. (Table 1).

With tissue Doppler imaging, statistically significant prolonged E: E's and E: E' ${ }_{\mathrm{L}}$ showed diastolic dysfunction in cirrhotics as compared to controls $(\mathrm{P}<0.001)$. Using cut off $\mathrm{E}$ : E's ratio less than 8 , the frequency of diastolic dysfunction in cirrhotics was $64.2 \%$ (Table 3). The median EDT in cirrhotic group and controls was $170 \mathrm{~ms}$ (100-229) and $204 \mathrm{~ms}$ (190220) respectively and difference was statistically significant. $(P<0.01)$. The E: A ratio did not differ in cirrhotic group and controls. IVRT showed diastolic dysfunction in cirrhotics as compared to controls $(\mathrm{P}=0.55)$. MPI also revealed statistically significant difference between cirrhotic and control group $(\mathrm{P}<0.01)$. The end diastolic volume, end systolic volume and ejection fraction did not differ in cirrhotic and control group (Table 2).

On subgroup analysis of cirrhotic group, LV mass was higher in alcoholic group as compared to non-alcoholic group, but the difference was statistically insignificant. The cardiac chamber dimensions, E: A ratio, EDT, E: E's, E: E' ${ }_{L}$ ratio and MPI did not differ in alcoholic and non-alcoholic cirrhotic group (Table 4). The diastolic dysfunction differences were also statistically significant when alcoholic and non-alcoholic cirrhotics were individually compared to controls (Table 4).

On comparing echocardiographic parameters in different Child-Turcotte-Pugh classes, left ventricular dimension in diastole in Child class $\mathrm{C}$ was significantly different from Child $A$ and B. There was no difference in other echocardiographic parameters among the above groups.

Brain natriuretic factor (BNP) was evaluated in 50 patients of cirrhosis and no difference was seen in both cirrhotic groups. BNP levels were higher in Child $\mathrm{C}$ cirrhosis as compared to Child A and B. Statistically significant difference was seen between Child A and C, but there was no difference between child A vs. B or Child B vs. C (Figure 2).

\begin{tabular}{|c|c|c|c|}
\hline $\begin{array}{c}\text { Echocardiography } \\
\text { Parameters }\end{array}$ & Cirrhotics & Control & P value \\
\hline $\begin{array}{c}\text { LV dimension in } \\
\text { diastole }(\mathrm{cm})\end{array}$ & $\begin{array}{c}4.3 \\
(3.2-5.5)\end{array}$ & $\begin{array}{c}4.3 \\
(3.8-4.9)\end{array}$ & .0335 \\
\hline $\begin{array}{c}\text { LV dimension } \\
\text { in systole (cm) }\end{array}$ & $\begin{array}{c}2.6 \\
(2-3.8)\end{array}$ & $\begin{array}{c}2.9 \\
(2.6-3.4)\end{array}$ & .001 \\
\hline $\begin{array}{c}\text { Septal thickness } \\
\text { diastole (cm) }\end{array}$ & $\begin{array}{c}0.9 \\
(0.8-1.2)\end{array}$ & $\begin{array}{c}1 \\
(0.8-1.2)\end{array}$ & .064 \\
\hline $\begin{array}{c}\text { Posterior wall } \\
\text { thickness in diastole (cm) }\end{array}$ & $\begin{array}{c}1 \\
(0.7-1.6)\end{array}$ & $\begin{array}{c}1 \\
(0.7-1.2)\end{array}$ & .360 \\
\hline Left atrial size (cm) & $\begin{array}{c}3.4 \\
(2.2-4.7)\end{array}$ & $\begin{array}{c}3.4 \\
(3-3.8)\end{array}$ & .711 \\
\hline $\begin{array}{c}142 \\
\text { Left ventricular } \\
\text { mass (g) }\end{array}$ & $\begin{array}{c}137 \\
(74-365)\end{array}$ & .900 \\
\hline
\end{tabular}

\begin{tabular}{|c|c|c|c|}
\hline $\begin{array}{c}\text { End diastolic } \\
\text { volume (mL) }\end{array}$ & $\begin{array}{c}87 \\
(44-120)\end{array}$ & $\begin{array}{c}88 \\
(57-107)\end{array}$ & .537 \\
\hline $\begin{array}{c}\text { End systolic } \\
\text { volume (mL) }\end{array}$ & $\begin{array}{c}31 \\
(14-45)\end{array}$ & $\begin{array}{c}34 \\
(24-47)\end{array}$ & .230 \\
\hline $\begin{array}{c}\text { Ejection } \\
\text { Fraction }\end{array}$ & $\begin{array}{c}65 \\
(47-76)\end{array}$ & $.55-69)$ & .084 \\
\hline Table 1: Cardiac Chamber Dimension Comparison \\
between Cirrhotics and Controls \\
\hline
\end{tabular}

*Data in above table is expressed as median and range, MannWitney test.

\begin{tabular}{|c|c|c|c|c|}
\hline $\begin{array}{c}\text { Echo- } \\
\text { cardiographic } \\
\text { parameters }\end{array}$ & Alcoholics & $\begin{array}{c}\text { Non } \\
\text { alcoholics }\end{array}$ & Control & $\begin{array}{c}\mathbf{P} \\
\text { value }\end{array}$ \\
\hline E: A ratio & $\begin{array}{c}1.21 \\
(1-1.5)\end{array}$ & $\begin{array}{c}1.16 \\
(1-1.47)\end{array}$ & $\begin{array}{c}1.2 \\
(1-1.3)\end{array}$ & .256 \\
\hline $\begin{array}{c}\text { E Deceleration } \\
\text { time (ms) }\end{array}$ & $\begin{array}{c}170 \\
(144-229)\end{array}$ & $\begin{array}{c}170 \\
(100-223)\end{array}$ & $\begin{array}{c}204 \\
(190-220)\end{array}$ & .001 \\
\hline $\begin{array}{c}\text { Isovolumic } \\
\text { relaxation } \\
\text { time (ms) }\end{array}$ & 76 & 77 & 84 & 0.149 \\
\hline E/E's ratio & 8.0 & 9 & 6.5 & .001 \\
\hline $\begin{array}{c}(5.2-160) \\
(55-100)\end{array}$ & $(4.7-16)$ & $(5-9)$ & $56)$ \\
\hline E/E' ratio & 5 & $\begin{array}{c}6.8 \\
(3.6-13.11)\end{array}$ & $\begin{array}{c}5.48-14.4) \\
(3.75-8.3)\end{array}$ & 0.002 \\
\hline $\begin{array}{c}\text { Myocardial } \\
\text { performance } \\
\text { index }\end{array}$ & $\begin{array}{c}0.48 \\
(0.4-0.6)\end{array}$ & $\begin{array}{c}0.43 \\
(0.3-0.6)\end{array}$ & $\begin{array}{c}0.35 \\
(0.2-0.4)\end{array}$ & .001 \\
\hline \multicolumn{7}{|c|}{$\begin{array}{c}\text { Table 2. Diastolic Parameters on Echocardiography } \\
\text { among Alcoholics, Non-alcoholics and Controls }\end{array}$} \\
\hline
\end{tabular}

E-early diastolic velocity of mitral inflow, A- late diastolic velocity of mitral inflow, E's- septal mitral annular velocity, $\mathrm{E}_{\mathrm{L}}^{\prime}$ - lateral mitral annular velocity ${ }^{*}$ Data in above table is expressed as median and range, Kruskal Wallis $\mathrm{H}$ test.

\begin{tabular}{|c|c|c|c|c|}
\hline $\begin{array}{l}\text { Diastolic } \\
\text { Function } \\
\end{array}$ & \multicolumn{2}{|c|}{$\begin{array}{l}\text { Disease } \\
(\mathrm{N}=70) \\
\end{array}$} & \begin{tabular}{|c|} 
Control \\
$(\mathrm{N}=20)$ \\
\end{tabular} & $\begin{array}{c}p- \\
\text { value }\end{array}$ \\
\hline $\begin{array}{c}\text { Abnormal } \\
(\mathrm{n}, \%)\end{array}$ & \multicolumn{2}{|c|}{$45(64.2 \%)$} & $2(10 \%)$ & $<0.001$ \\
\hline \begin{tabular}{|l|} 
Diastolic \\
Function \\
\end{tabular} & $\begin{array}{c}\text { Alcoholic } \\
(\mathrm{N}=20)\end{array}$ & $\begin{array}{c}\text { Non-alcoholic } \\
(\mathrm{N}=50)\end{array}$ & $\begin{array}{l}\text { Control } \\
(\mathrm{N}=20) \\
\end{array}$ & $\mathrm{p}$-value \\
\hline $\begin{array}{c}\text { Abnormal } \\
(\mathrm{n}, \%)\end{array}$ & $\begin{array}{c}11 \\
(55 \%)\end{array}$ & $32(64 \%)$ & $\begin{array}{c}2 \\
(10 \%) \\
\end{array}$ & $<0.001$ \\
\hline $\begin{array}{l}\text { Diastolic } \\
\text { function }\end{array}$ & $\begin{array}{l}\text { Child A } \\
(\mathrm{N}=17)\end{array}$ & $\begin{array}{l}\text { Child B } \\
(\mathrm{N}=22)\end{array}$ & $\begin{array}{l}\text { Child C } \\
(\mathrm{N}=31)\end{array}$ & $\mathrm{p}$-value \\
\hline $\begin{array}{c}\text { Abnormal } \\
(\mathrm{n}, \%)\end{array}$ & 7 (41.2\%) & $\begin{array}{c}15 \\
(68.1 \%) \\
\end{array}$ & $\begin{array}{c}21 \\
(67.7 \%) \\
\end{array}$ & 0.143 \\
\hline
\end{tabular}

\begin{tabular}{|c|c|c|c|}
\hline $\begin{array}{c}\text { Echocardiographic } \\
\text { Parameters }\end{array}$ & Alcoholic & $\begin{array}{c}\text { Non- } \\
\text { alcohol }\end{array}$ & $\begin{array}{c}\text { P } \\
\text { value }\end{array}$ \\
\hline E: A ratio & $\begin{array}{c}1.21 \\
(1-1.5)\end{array}$ & $\begin{array}{c}1.16 \\
(1-1.47)\end{array}$ & 0.96 \\
\hline $\begin{array}{c}\text { E Deceleration } \\
\text { time (ms) }\end{array}$ & $\begin{array}{c}170 \\
(144-229)\end{array}$ & $\begin{array}{c}170 \\
(100-223)\end{array}$ & 0.93 \\
\hline $\begin{array}{c}\text { Isovolumic Relaxation } \\
\text { time (ms) }\end{array}$ & $\begin{array}{c}76 \\
(58-100)\end{array}$ & $\begin{array}{c}77 \\
(55-100)\end{array}$ & 0.89 \\
\hline E/E's ratio & $\begin{array}{c}8.0 \\
(5.2-16.5)\end{array}$ & $\begin{array}{c}9 \\
(4.7-16)\end{array}$ & 0.13 \\
\hline Myocardial & $\begin{array}{c}0.48 \\
(0.4-0.6)\end{array}$ & $\begin{array}{c}0.43 \\
(0.3-0.6)\end{array}$ & 0.74 \\
\hline performance index & Table 4. Diastolic Dysfunction in Alcoholics \\
and Non-alcoholics group & \\
\hline
\end{tabular}


E-early diastolic velocity of mitral inflow, A- late diastolic velocity of mitral inflow, Ea- septal mitral annular velocity, $E_{L}$ - lateral mitral annular velocity *Data in above table is expressed as median and range, Mann-Witney test.

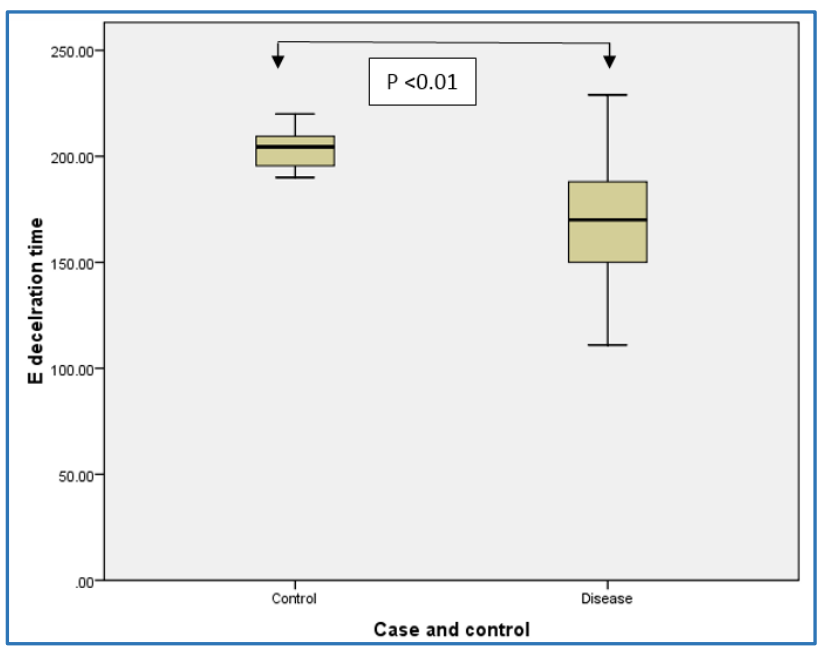

Figure 1. Box Plot Graph Showing E Deceleration time in Cirrhotics and Control

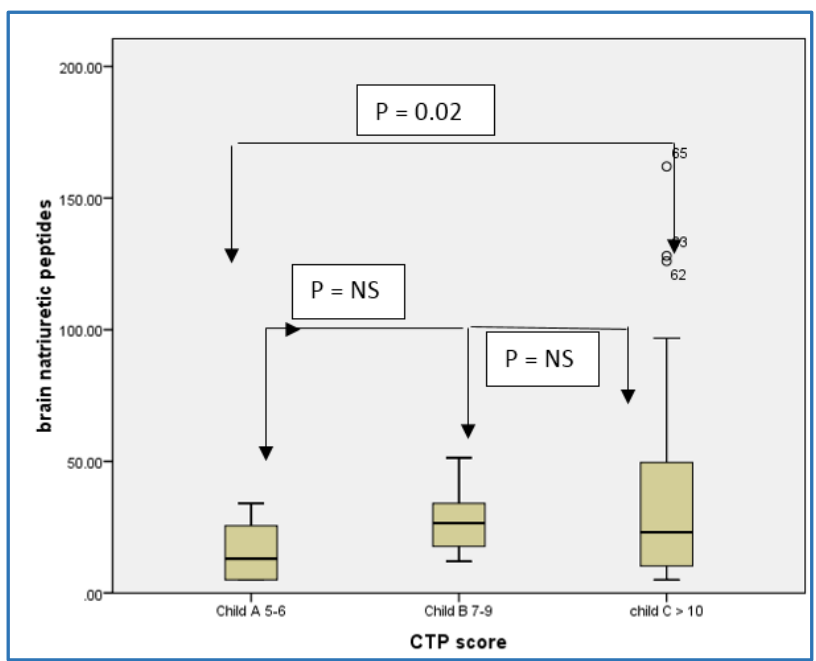

Figure 2. Box Plot Graph showing Serum BNP Levels

\section{DISCUSSION}

Our study showed frequency of diastolic dysfunction among cirrhotics was $64.2 \%$ and was comparable among alcoholic and non-alcoholic cirrhotics. The diastolic functions were assessed with tissue Doppler image, EDT, E/A ratio and IVRT. With cut-off value of E: E's ratio $\leq 8$, the frequency of diastolic dysfunction in cirrhotics was $64.2 \%$ and on comparing the frequency among Child A, B and C were $41.2 \%, 68.1 \%$ and $67.7 \%$ respectively, but this difference was not statistically significant. The E: E's is a specific marker of diastolic dysfunction, it has not been evaluated as marker for diastolic dysfunction in cirrhotics in previous studies. In studies on essential hypertension, $\mathrm{E}: \mathrm{E}^{\prime} \mathrm{s}$ and $\mathrm{E}$ : $\mathrm{E}_{\mathrm{L}}^{\prime}$ ratio provided prognostic significance in diastolic dysfunction. ${ }^{7}$ The results in our study were similar to previous studies showing evidence of diastolic dysfunction among cirrhotics.8,9 EDT was shorter in cirrhotic group as compared to controls. The median E deceleration time (ms) in cirrhotics and controls was $170(100-229)$ and 204 (190 - 220) respectively and difference was statistically significant $(\mathrm{P}<0.01)$. This result was in contrast to previous studies where EDT was prolonged in cirrhotics as compared to controls. ${ }^{8}$ EDT reflects impedance to LV filling and varies with severity of diastolic dysfunction, the value increases in grade 1 diastolic dysfunction and as severity worsens it tends to pseudonormalise or decreases. ${ }^{10} \mathrm{E} / \mathrm{A}$ ratio and IVRT did not show statistically significant difference among cirrhotics and controls. Similar observation was seen in previous studies and it could be due to pseudonormalisation, in spite of diastolic dysfunction. 8,10,11 However, there have been reports of a decrease in the E:A ratio in cirrhotics, with observations of a statistically significant decrease in the $\mathrm{E}: \mathrm{A}$ ratio in cirrhotics with ascites compared to cirrhotics without ascites and controls. ${ }^{9}$

The pathogenesis of cardiac dysfunction in cirrhosis is poorly understood and is likely related to combination of factors that include impairment of stimulatory $\beta$-adrenergic receptor signalling pathways, altered plasma membrane physicochemical properties, and over activity of negativeinotropic factors such as nitric oxide, carbon monoxide and endocannabinoid systems. ${ }^{12}$

The cardiac chamber evaluation showed higher LVDD and smaller LVSD in cirrhotics as compared to controls. However, in our study, indexed values of dimensions were not used and none of the patients had abnormal dimensions comparing to reference range as per American Society of Echocardiography recommendations. In literature, few studies have shown increased or unchanged left ventricular diastolic dimension. ${ }^{13}$ SWT, PWT in diastole and left atrial size were comparable among cirrhotics and controls. The left ventricular mass (LVM) was higher in cirrhotics as compared to controls and the difference was statistically significant between cirrhotics and controls. In other studies left ventricular mass has been shown to be higher in $25 \%$ of cirrhotics and normal in $75 \% .^{13}$ The enlarged cardiac dimensions could be secondary to haemodynamic overload and activation of the neuroendocrine system. ${ }^{11}$ Necropsied cardiac tissue from cirrhotic patients revealed many histological changes including subendocardial and myocyte oedema, patchy fibrosis, muscle hypertrophy, exudation, nuclear vacuolation, and unusual pigmentation. ${ }^{14}$

Neither the end-diastolic nor the end-systolic volume was significantly different in the cirrhotic patients compared with the controls. This result was in contrast to other studies that have shown increased end diastolic volume and decreased end systolic volume as part of hyperdynamic circulation. ${ }^{15}$ In patients with cirrhosis due to systemic peripheral vasodilatation resulting from increased endogenous nitric oxide, the left ventricular after load decreases and auto treatment occurs, masking the overt heart failure. 15 The left ventricular ejection fraction was higher in cirrhotics, but the difference was not statistically significant among cirrhosis and controls. There was no difference in ejection fraction among cirrhosis due to alcoholic and non-alcoholic group. This result is in contrast to few studies which have shown higher ejection fraction in viral cirrhosis as compared to alcoholic cirrhosis due to underlying alcoholic cardiomyopathy. ${ }^{16}$

Myocardial Performance Index (MPI) as a surrogate of systolic function: In our study, MPI was prolonged in 
cirrhotics $(\mathrm{P}=<0.01)$. In subgroup analysis, there was no difference between alcoholic and non-alcoholic cirrhosis.

Because of the potent systolic parameters that contribute to the MPI, such as isovolumic contraction time (ICT) and ejection time (ET), the index detects with reliability current alterations of LV systolic function. Thus, the index maintains a strong inverse relation with ejection fraction. The higher the value of the index, the lower the ejection fraction and vice versa. The superiority of the Tei index is attributed to its ability to reflect the combined systolic and diastolic performance (in contrast with the systolic ejection fraction), an advantage more evident in cases of isolated LV diastolic dysfunction. Furthermore, the index, as a Doppler parameter, is independent of ventricular geometry, while ejection fraction is less reliable in cases of anatomic anomalies of $\mathrm{LV}$, such as those following MI.

MPI as a surrogate of diastolic function LV systolic as well as diastolic dysfunction induces impaired relaxation (prolongation of isovolumic relaxation time, IRT). The fact that both phases of LV function are simultaneously reflected in the diastolic parameter of the index (IRT) renders the index sensitive in the identification of impaired relaxation. Thus, myocardial performance index has a close correlation with diastolic haemodynamic indices of relaxation $(-\mathrm{dP} / \mathrm{dt}$ and tau) and appears superior to conventional diastolic parameters in the detection of impaired relaxation.

QTc interval was not statistically different among cirrhotics and controls. In previous studies, QTc interval was increased in $45 \%$ of cirrhotics and is related to severity of underlying liver disease. ${ }^{17}$

In our study, there was no correlation between the severity of liver disease calculated by Child Turcotte Pugh score or Model for end stage liver disease (MELD) and cardiac changes on echocardiography or electrocardiography. There have been few reports that cardiac changes correlate with severity of liver disease ${ }^{11}$.

Serum BNP is synthesised mainly by myocytes of the left ventricle in response to volume overload or an increase in left ventricular end diastolic pressure. Serum BNP levels have been found to be elevated in decompensated cirrhosis. ${ }^{18}$ Levels in compensated cirrhosis are controversial as values have been either normal or decreased. In our study, levels of BNP were significantly higher in Child $\mathrm{B}$ and Child $\mathrm{C}$ as compared to Child A (Figure 2). Similar result was also seen in a previous study with higher levels in decompensated cirrhosis. ${ }^{18}$ In our study, there was no correlation seen between levels of BNP and cardiac changes as described earlier. ${ }^{6}$

The constellation of features of cardiac dysfunction, termed as cirrhotic cardiomyopathy can be defined as 1) baseline increased cardiac output but blunted ventricular response to stimuli, 2) systolic and/or diastolic dysfunction, 3) absence of overt left ventricular failure at rest, 4) electrophysiological abnormalities including prolonged QT interval on electrocardiography and chronotropic incompetence. Not all features are required for diagnosis of cardiomyopathy. ${ }^{19}$

Confounders such as comorbidities and complications of cirrhosis can alter cardiovascular function and were excluded from this study. The patients included in study were on low salt diet and previously treated with diuretics. Diuretics were stopped at least 7 days prior to evaluation, but combined effect of low salt and long-lasting effect of spironolactone can result in volume contraction thus blunting hyperdynamic circulation.

In our study, cardiac changes seem to be due to cirrhosis rather than alcohol as there was no statistically significant difference between alcoholic and non-alcoholic cirrhotic groups.

The patients included in the study had diastolic dysfunction as compared to alcoholic cardiomyopathy which results in systolic dysfunction.

\section{CONCLUSION}

In conclusion, our study demonstrated that $64.2 \%$ cirrhotics had diastolic dysfunction and cardiac changes were due to cirrhosis rather than other causes. There was no difference in alcoholic and non-alcoholic cirrhosis. None in study had systolic dysfunction. There was no correlation of degree of cardiac dysfunction with severity of liver disease.

\section{REFERENCES}

[1] Lee SS. Cardiac abnormalities in liver cirrhosis. West J Med 1989;151(5):530-5.

[2] Kowalski HJ, Abelmann WH. The cardiac output at rest in Laennec's cirrhosis. J Clin Invest 1953;32(10):102533.

[3] Franco D, Vons C, Traynor O, et al. Should portosystemic shunt be reconsidered in the treatment of intractable ascites in cirrhosis? Arch Surg 1988;123(8):987-91.

[4] Lebrec D, Giuily N, Hadengue A, et al. Transjugular intrahepatic portosystemic shunts: comparison with paracentesis in patients with cirrhosis and refractory ascites: a randomized trial. French group of clinicians and a group of biologists. J Hepatol 1996;25(2):13544.

[5] Piscaglia F, Zironi G, Gaiani S, et al. Systemic and splanchnic hemodynamic changes after liver transplantation for cirrhosis: a long-term prospective study. Hepatology 1999;30(1):58-64.

[6] Wong F, Siu S, Liu P, et al. Brain natriuretic peptide: is it a predictor of cardiomyopathy in cirrhosis? Clin Sci (Lond) 2001;101(6):621-8.

[7] Schillaci G, Pasqualini L, Verdecchia P, et al. Prognostic significance of left ventricular diastolic dysfunction in essential hypertension. J Am Coll Cardiol 2002;39(12):2005-11.

[8] Alexander J, Mishra P, Desai N, et al. Cirrhotic cardiomyopathy: Indian scenario. J Gastroenterol Hepatol 2007;22(3):395-9.

[9] Merli M, Valeriano V, Funaro S, et al. Modifications of cardiac function in cirrhotic patients treated with transjugular intrahepatic portosystemic shunt (TIPS). Am J Gastroenterol 2002;97(1):142-8.

[10] Oh JK, Hatle L, Tajik AJ, et al. Diastolic heart failure can be diagnosed by comprehensive two-dimensional and doppler echocardiography. J Am Coll Cardiol 2006;47(3):500-6.

[11] Blendis L, Wong F. Is there a cirrhotic cardiomyopathy? Am J Gastroenterol 2000;95(11):3026-8.

[12] Liu H, Song D, Lee SS. Cirrhotic cardiomyopathy. Gastroenterol Clin Biol 2002;26(10):842-7. 
[13] Valeriano V, Funaro S, Lionetti R, et al. Modification of cardiac function in cirrhotic patients with and without ascites. Am J Gastroenterol 2000;95(11):3200-5.

[14] Hall EM, Olsen AY, Davis FE. Portal cirrhosis: clinical and pathologic review of 782 cases from 16,600 necropsies. Am J Pathol 1953;29(6):993-1027.

[15] Finucci G, Desideri A, Sacerdoti D, et al. Left ventricular diastolic function in liver cirrhosis. Scand J Gastroenterol 1996;31(3):279-84.

[16] Piscaglia F, Valgimigli M, Rapezzi C, et al. Left ventricular volumes in liver cirrhosis. Dig Liver Dis 2000;32(5):392-7.
[17] Bernardi M, Calandra S, Colantoni A, et al. Q-T interval prolongation in cirrhosis: prevalence, relationship with severity, and etiology of the disease and possible pathogenetic factors. Hepatology 1998;27(1):28-34.

[18] La Villa G, Romanelli RG, Casini Raggi V, et al. Plasma levels of brain natriuretic peptide in patients with cirrhosis. Hepatology 1992;16(1):156-61.

[19] Al Hamoudi W, Lee SS. Cirrhotic cardiomyopathy. Ann Hepatol 2006;5(3):132-9. 